\title{
Adenylate kinase locus 1 genetic polymorphism and type 2 diabetes
}

\author{
Fulvia Gloria-Bottini ${ }^{1 *}$, Elena Antonacci ${ }^{2}$, Anna Neri $^{1}$, Andrea Magrini $^{1}$, Egidio Bottini $^{1}$ \\ ${ }^{1}$ Division of Biopathology of Human Population and Environmental Pathology, Department of Biopathology and Imaging Diagnos- \\ tics, University of Rome Tor Vergata, Rome, Italy; ${ }^{*}$ Corresponding Author: gloria@med.uniroma2.it \\ ${ }^{2}$ Centre of Diabetology, Local Sanitary Unit, Penne, Italy.
}

Received 9 August 2010; revised 14 February 2011; accepted 18 August 2011

\section{ABSTRACT}

$A K_{1}$ catalyzes the reversible reaction ATP+AMP $\Leftrightarrow 2 A D P$ thus contributing to the regulation of relative concentration of these important nucleotides. Intracellular ATP is a storage of energy for cellular processes, moreover extracellular ATP together with ADP, AMP and adenosine are critical signalling molecule for sending messages to nearby cells acting on P1 and P2 receptors. AK $\mathrm{K}_{1}$ shows a genetic polymorphism and recently our group has shown that the correlation between blood glucose and glycated haemoglobin in T2D is dependent on $A K_{1}$ phenotype. In the present paper we have carried further studies on the relationship between $A K_{1}$ phenotypes and T2D. Possible interactions with ABO blood groups and ACP1 polymorphism have also been investigated. We have re-examined the data on $\mathbf{2 8 0}$ subjects with type 2 diabetes from the White population of Penne (Central Italy). 384 consecutive healthy newborns from the same population have been also studied. A three way contingency table analysis was carried out according to Sokal and Rohlf and other statistical analyses by SPSS programs. T2D patients with $A K_{1} 2-1$ phenotype have higher values of blood glucose level and glycated haemoglobin and an increased tendency to dyslipidemia and retinopathy. In addition there is an interaction of $A K_{1}$ with $A B O$ blood groups and with $\mathrm{ACP}_{1}$ polymorphism. The different activity between $A K_{1}$ phenotypes could influence the relative concentration of ATP, ADP, AMP and adenosine with important effects on metabolic activity thus explaining the association of $A K_{1}$ with clinical manifestation of T2D.

Keywords: AK; T2D; Glycemia; ATP;
Glycated Haemoglobin

\section{INTRODUCTION}

Adenylate kinase (AK) is an ubiquitous enzyme that catalyzes the nucleotide phosphoryl interconversion ATP + AMP $\Leftrightarrow 2 A D P$. The products of this reaction are involved in the regulation of many cellular function and relationship. Intracellular ATP is a storage of energy for cellular processes. The energy from extracellular ATP is used for sending messages to nearby cells.

At first, extracellular ATP was seen simply as a neurotransmitter, subsequently was studied the mechanism of interactions between extracellular ATP signalling with other signalling systems outside the cells named ectoATPases. This large family of AK enzyme removes from ATP, one by one, its phosphates producing adenosine diphosphate (ADP), adenosine monophosphate (AMP) and adenosine that have different effect on several cells by binding themselfes to P2 family (for ADP, AMP) and to P1 (for adenosine) receptors [1].

The family of AK enzymes includes seven genes, $A K_{1}-\mathrm{AK}_{7}$, with each other different functions,molecular weight and kinetic property. The network of these enzymes are distributed throughout intracellular compartments, interstitial space and body fluids to regulate energetic and metabolic signaling circuits and to fasten an efficient economy of cell energy, signal communication and stress response.Mutations in $\mathrm{AK}_{1}, \mathrm{AK}_{2}$ or $\mathrm{AK}_{7}$ genes have been found associated with hemolytic anemia, reticular dysgenesis and ciliary dyskinesia [2].

Adenylate kinase locus $1\left(\mathrm{AK}_{1}\right)$ belongs to $\mathrm{AK}$ family and plays an important role in the synthesis of nucleotides requested for many metabolic functions. It is present in the cytosol of skeletal muscle, brain, and erythrocyte. The enzyme is polymorphic and shows three phenotypes with different activity, in the order $\mathrm{AK}_{1} 1>$ $\mathrm{AK}_{1} 2-1>\mathrm{AK}_{1} 2$ corresponding to the presence of two codominant alleles, $\mathrm{AK}_{1} * 1$ and $\mathrm{AK}_{1} * 2$ at an autosomal 
locus on chromosome 9. Rare alleles $\mathrm{AK}_{1} * 3, \mathrm{AK}_{1} * 4$ and $\mathrm{AK}_{1} * 5$ have been also referred.

$\mathrm{AK}_{1}$ was identified because of its association with a rare genetic disorder causing nonspherocytic hemolytic anemia where a mutation in the $\mathrm{AK}_{1}$ gene was found to reduce the catalytic activity of the enzyme and the replacement of Arg-128 with Trp [3].

Our group has recently shown that the correlation between blood glucose and glycated haemoglobin in T2D is dependent on $\mathrm{AK}_{1}$ phenotype. In addition, blood glucose is significantly higher in $\mathrm{AK}_{1} 2-1$ than in $\mathrm{AK}_{1} 1$ subjects [4]. This prompted us to study in more details the relationship between $\mathrm{AK}_{1}$ and T2D. We have also considered possible interactions of $\mathrm{AK}_{1}$ with $\mathrm{ABO}$ blood groups that is linked to $\mathrm{AK}_{1}$ [5] and with $\mathrm{ACP}_{1}$ that is associated with clinical manifestation of T2D [6].

\section{MATERIAL AND METHODS}

We have re-examined the data on 278 subjects with type 2 diabetes from the population of Penne (Italy) and have studied 384 consecutive healthy newborns from the same population. T2D patients have been considered in a previous study [6] and were a random sample of a population of about 2000 subjects under care at Centre of Diabetology of the local Hospital. Penne is a rural town located in Eastern side of Central Italy. This homogenous population are the descendant of an old Italic population called "Vestini". The total number of subjects shown in the tables are not always the same due to some random missing value for the variables considered.

The patients have been controlled in the Centre of Diabetology according to a regular schedule. In occasion of the control blood glucose and glycated haemoglobin levels have been measured (more than 9 hours since the last meal). Blood sample for determination of genetic markers were also obtained. Written informed consent was obtained from patients and from mothers of newborns to participate to this study that was approved by the Institutional Review Board.

\subsection{Laboratory Analysis}

Serum glucose concentration was measured by the automated Roche/Hitachi cobas C501 system based on enzymatic reaction with exochinase. Glycated haemoglobin was determined using the Menarini Diagnostics HA-8160 automated equipment based on inverse exchange cationic chromatography.

$\mathrm{AK}_{1}$ phenotype was determined by starch gel electrophoresis of haemolysate [7]. Samples were examined at $\mathrm{pH} 7$. The insert were made from Whatman, $n^{\circ} 3$ filter paper. After electrophoresis the gels were sliced and then covered with a $0.75 \%$ agar solution at $45^{\circ} \mathrm{C}$ made in 0.1
$\mathrm{M}$ tris buffer $\mathrm{pH} 8$ and containing glucose $10 \mathrm{mM}$, magnesium chloride $20 \mathrm{mM}$, adenosine diphosphate (ADP) 1 $\mathrm{mM}$, nicotinammide adenine dinucleotide phosphate (NADP) $0.4 \mathrm{mM}$, phenazine methosulphate (PMS) $0.012 \%$, tetrazolium salt (MTT) $0.012 \%$, glucose-6-phosphate dehydrogenase (G6PD) 0.04 units/ml and hexokinase 0.08 units $/ \mathrm{ml}$. The agar was allowed to set and then the gel incubated at $37^{\circ} \mathrm{C}$ for two hours.

At the sites of AK activity ADP is converted into AMP and ATP. The ATP reacts with glucose in the presence of hexokinase to produce ADP and glucose-6-phosphate (G6P), this is oxidized to 6-phosphogluconate by G6PD with concomitant reduction of NADP. The reduced NADP in the presence of PMS causes the reduction of MTT to give a blue-coloured insoluble formazan, which is thus deposited at the sites of AK activity. In Caucasian populations three distinct types of electrophoretic pattern are recognized referred as $\mathrm{AK}_{1} 1, \mathrm{AK}_{1} 2-1$ and $\mathrm{AK}_{1} 2$ corresponding to the presence of two codominant alleles: $\mathrm{AK}_{1} * 1$ and $\mathrm{AK}_{1} * 2$ at an autosomal locus.

$\mathrm{ACP}_{1}$ phenotype has been determined by starch gel electrophoresis on red blood cell haemolysates according to Spencer et al. [8]. The acid phosphatase pattern is revealed by a solution of phenolphthalein diphosphate: The addendum of ammonium solution reveals the area where phenophtalein has been liberated in the areas of gel where $\mathrm{ACP}_{1}$ activity is present. In European populations, the presence of three common alleles $* \mathrm{~A},{ }^{*} \mathrm{~B}$ and ${ }^{*} \mathrm{C}$ determines the occurrence of six phenotypes with enzymatic activity increasing in the order: $\mathrm{A}<\mathrm{AB}<\mathrm{B}<$ $\mathrm{AC}<\mathrm{BC}<\mathrm{C}$. Each of the homozygous A, B, and C phenotypes are composed of two fractions $\mathrm{F}$ and $\mathrm{S}$ corresponding to a fast and slow component of electrophoretic pattern. Heterozygous phenotypes have a pattern corresponding to a mixture of homozygous types.

\subsection{Statistical Analysis}

Statistical analyses have been carried out by SPSS program [9]. Three way contingency table analysis has been performed according to Sokal and Rohlf [10].

\section{RESULTS}

Clinical and demographic data in subjects with T2D and in healthy newborns are shown in Table 1.

In T2D the frequency of $A_{1} 2-1$ is slightly greater in comparison to healthy newborns but the difference is not statistically significant (see Table 2). The data suggest that $\mathrm{Ak}_{1}$ may not be an important factor primarily involved in the susceptibility to type 2 diabetes.

The distributions of blood glucose and glycated $\mathrm{Hb}$ are shown in Table 3. Both parameters show a greater value in $\mathrm{AK}_{1} 2-1$ than in $\mathrm{AK}_{1} 1$ but only for blood glucose 
Table 1. Clinical and demographic data of the samples studied.

\begin{tabular}{lcccc}
\hline & Mean & S.E. & \%Proportion & Total ${ }^{\circ}$ \\
\hline T2D & & & & \\
Age (yrs) & 66 & 0.59 & & 280 \\
Age at onset of disease (yrs) & 54 & 0.65 & & 275 \\
Duration of disease (yrs) & 11.9 & 0.48 & & 269 \\
BMI & 29.5 & 0.29 & & 277 \\
Male proportion & & & $47 \%$ & 279 \\
Dyslipidemia & & & $26.8 \%$ & 276 \\
Healthy Newborns & & & & \\
Male proportion & & & $47.6 \%$ & 424 \\
Birthweight (g) & 3348.3 & 22.0 & & 417 \\
Gestational age (wks) & 39.7 & 0.06 & & 411 \\
\hline
\end{tabular}

Table 2. Distribution of $\mathrm{AK}_{1}$ phenotypes in T2D and in healthy newborns.

\begin{tabular}{lccc}
\hline & $\mathrm{AK}_{1} 1$ & $\mathrm{AK}_{1} 2-1$ & Total $^{\circ}$ \\
\hline T2D subjects & & & \\
& $93.5 \%$ & $6.5 \%$ & 278 \\
Healthy newborns & & & \\
& $94.3 \%$ & $5.7 \%$ & 384 \\
Chi square test of independence & & \\
& $\chi^{2}$ & $\mathrm{df}$ & $\mathrm{p}$ \\
0.054 & 1 & 0.816 \\
\hline
\end{tabular}

Table 3. Blood glucose and glycated haemoglobin levels according to $\mathrm{AK}_{1}$ phenotype in $\mathrm{T} 2 \mathrm{D}$.

\begin{tabular}{lcccc}
\hline & \multicolumn{2}{c}{ Blood glucose } & \multicolumn{2}{c}{ Glycated $\mathrm{Hb}$} \\
\cline { 2 - 5 } & Mean & S.E. & Mean & S.E. \\
\hline $\mathrm{AK}_{1} 1$ & 133.9 & 2.3 & 7.51 & 0.11 \\
$\mathrm{AK}_{1} 2-1$ & 156.9 & 11.8 & 8.18 & 0.39 \\
T-test for differences between means & & \\
\multicolumn{2}{c}{$\mathrm{p}=0.015$} & \multicolumn{2}{c}{$\mathrm{p}=0.121$} \\
\hline
\end{tabular}

the difference is statistically significant.

The proportion of subjects with dyslipidemia and retinopathy is greater in $\mathrm{AK}_{1} 2-1$ than in $\mathrm{AK}_{1} 1$ but the difference does not reach the level of statistical significance (see Table 4).

In T2D the proportion of AK2-1 phenotype is very high in B blood group and very low in A group. The difference between A and B blood groups is highly signifi- cant (O.R. = 10.173 C.I. 2.151-39.163). No significant association has been observed between $\mathrm{ABO}$ and $\mathrm{AK}_{1}$ phenotypes in healthy newborns (see Table 5).

Table 6 shows in T2D subjects the distribution of blood glucose and glycated $\mathrm{Hb}$ in relation to the joint $\mathrm{ABO}-\mathrm{AK}_{1}$ phenotypes. Both parameters in $\mathrm{A}$ and $\mathrm{O}$ subjects show higher values in those carrying the $\mathrm{AK}_{1} 2-1$ phenotype than in those carrying the $\mathrm{AK}_{1} 1$ phenotype while in B subjects there is a slight tendency to a reduction of both parameters in $\mathrm{AK}_{1} 2-1$ phenotype as compared to Ak1 phenotype.

Figure 1 displays the relationship between serum glucose level and ACP1 enzymatic activity in $\mathrm{AK}_{1} 1$ and $\mathrm{AK}_{1}$ 2-1 subjects with T2D. In $\mathrm{AK}_{1} 1$ phenotype the concentration of serum glucose is positively correlated with ACP1 activity while in $\mathrm{AK}_{1} 2-1$ phenotype the association follows an opposite pattern.

\section{DISCUSSION}

The present data show that $\mathrm{T} 2 \mathrm{D}$ patients with $\mathrm{AK}_{1} 2-1$ phenotype have higher values of blood glucose level and glycated haemoglobin and have an increased tendency to dyslipidemia and retinopathy. In addition there is an interaction of $\mathrm{AK}_{1}$ with $\mathrm{ABO}$ blood groups and $\mathrm{ACP}_{1}$ polymorphism.

$\mathrm{AK}_{1}$ belongs to $\mathrm{AK}$ family and, at the sites of $\mathrm{AK}_{1}$ activity, ADP is converted into AMP and ATP. The reaction is reversible thus contributing to the regulation of relative concentration of these important nucleotides [1]. Extracellular ATP plays a physiological role in the maintenance of glucose homeostasis by regulating insulin secretion [11]. ATP is able to stimulate the release of pancreatic insulin modulating glucose transport via GLUT1 acting on P2 purinergic ionotropic (P2X) and P2 metabotropic (P2Y) receptors through a mechanism that involves beta-cell metabolism and a rise of intracellular calcium. P2Y receptors are deficient in fibroblasts from T2D patients [12].

Table 4. Prevalence of dyslipidemia and retinopathy in T2D subjects according to $\mathrm{AK}_{1}$ phenotype.

\begin{tabular}{|c|c|c|c|c|c|c|}
\hline & \multicolumn{3}{|c|}{ Dyslipidemia } & \multicolumn{3}{|c|}{ Retinopathy } \\
\hline & \multicolumn{2}{|c|}{$\begin{array}{l}\% \text { of subjects with } \\
\text { dyslipidemia }\end{array}$} & Total $n^{\circ}$ & \multicolumn{2}{|c|}{$\begin{array}{l}\% \text { of subjects with } \\
\text { retinopathy }\end{array}$} & Total $n^{\circ}$ \\
\hline $\mathrm{AK}_{1} 1$ & \multicolumn{2}{|c|}{$26.0 \%$} & 258 & \multicolumn{2}{|c|}{$15.5 \%$} & 258 \\
\hline $\mathrm{AK}_{1} 2-1$ & \multicolumn{2}{|c|}{$38.9 \%$} & 18 & \multicolumn{2}{|c|}{$27.8 \%$} & 18 \\
\hline \multicolumn{7}{|c|}{ Chi square test of independence } \\
\hline & $\chi^{2}$ & $\mathrm{df}$ & $\mathrm{p}$ & $\chi^{2}$ & $\mathrm{df}$ & $\mathrm{p}$ \\
\hline & 1.431 & 1 & 0.232 & 1.938 & 1 & 0.152 \\
\hline
\end{tabular}


Table 5. Distribution of the joint ABO-AK 1 phenotypes in T2D and in healthy newborns.

\begin{tabular}{|c|c|c|c|c|}
\hline & \multicolumn{4}{|c|}{ ABO phenotypes } \\
\hline & A & B & $\mathrm{AB}$ & $\mathrm{O}$ \\
\hline $\begin{array}{l}\text { Proportion of } \mathrm{AK}_{1} 2-1 \\
\text { phenotype }\end{array}$ & $2.7 \%$ & $21.9 \%$ & $0.0 \%$ & $6.2 \%$ \\
\hline Total $n^{\circ}$ & 112 & 32 & 4 & 130 \\
\hline \multicolumn{5}{|c|}{ Chi square test of independence } \\
\hline & $\chi^{2}$ & $\mathrm{df}$ & & $\mathrm{p}$ \\
\hline$A$ vs $B$ vs $A B$ vs $O$ & 15.497 & 3 & & 0.001 \\
\hline A vs $B$ vs $O$ & 15.012 & 2 & & 0.0005 \\
\hline A vs B & 11.378 & 3 & & 0.0007 \\
\hline \multicolumn{5}{|c|}{ O.R. $=10.173\left(\mathrm{~B}\right.$ vs $\mathrm{A} / \mathrm{AK}_{1} 2-1$ vs $\left.\mathrm{AK}_{1} 1\right)$} \\
\hline 95\% C.I. & \multicolumn{4}{|c|}{ 2.151-39.163 } \\
\hline \multicolumn{5}{|l|}{ Healthy newborns } \\
\hline $\begin{array}{l}\text { Proportion of } \mathrm{AK}_{1} 2-1 \\
\text { phenotype }\end{array}$ & $6.8 \%$ & $9.7 \%$ & $0.0 \%$ & $4.5 \%$ \\
\hline Total n $^{\circ}$ & 162 & 31 & 12 & 178 \\
\hline \multicolumn{5}{|c|}{ Chi square test of independence } \\
\hline & $\chi^{2}$ & df & & $\mathrm{p}$ \\
\hline $\mathrm{A}$ vs $\mathrm{B}$ vs $\mathrm{AB}$ vs $\mathrm{O}$ & 2.458 & 3 & & 0.483 \\
\hline A vs $B$ vs $O$ & 1.653 & 2 & & 0.437 \\
\hline A vs B & 0.036 & 1 & & 0.849 \\
\hline \multicolumn{5}{|c|}{ O.R.=1.471(B vs A/AK $2-1$ vs AK1) } \\
\hline & \multicolumn{2}{|c|}{ 95\% C.I. } & \multicolumn{2}{|c|}{$0.027-6.230$} \\
\hline
\end{tabular}

Three way contingency table analysis by a log linear model

$\mathrm{X}=\mathrm{ABO}(\mathrm{A}$ vs $\mathrm{B})$;

$\mathrm{y}=\mathrm{AK}_{1}\left(\mathrm{AK}_{1} 1\right.$ vs $\left.\mathrm{AK}_{1} 2-1\right)$;

$\mathrm{z}=$ sample (newborns vs T2D)

\begin{tabular}{cccc} 
& $G$ & df & $p$ \\
xyz interaction & 4.177 & 1 & 0.042 \\
\hline
\end{tabular}

ODDS ratio analysis (B vs A)/(T2D vs newborns)

\begin{tabular}{lcc} 
AK $_{1} 1$ phenotype & O.R. $=1.236$ & 95\%C.I. 0.656-2.330 \\
AK 2 -1 phenotype & O.R. 8.55 & 95\% C.I. 0.99-92.86 \\
\hline
\end{tabular}

An increase in the AMP/ATP ratio activates adenine monophosphate activated protein kinase (AMPK) that regulates glycolysis, glucose uptake, lipid oxidation, fatty acid synthesis, cholesterol synthesis and gluconeogenesis. [13,14]. The AMPK channelopathies are present in hyperinsulinemia, neonatal diabetes mellitus and are a risk factor for the aetiology of T2D [15,16].
Table 6. Blood glucose and glycated $\mathrm{Hb}$ in $\mathrm{T} 2 \mathrm{D}$ according to the joint $\mathrm{ABO}-\mathrm{AK}_{1}$ phenotype.

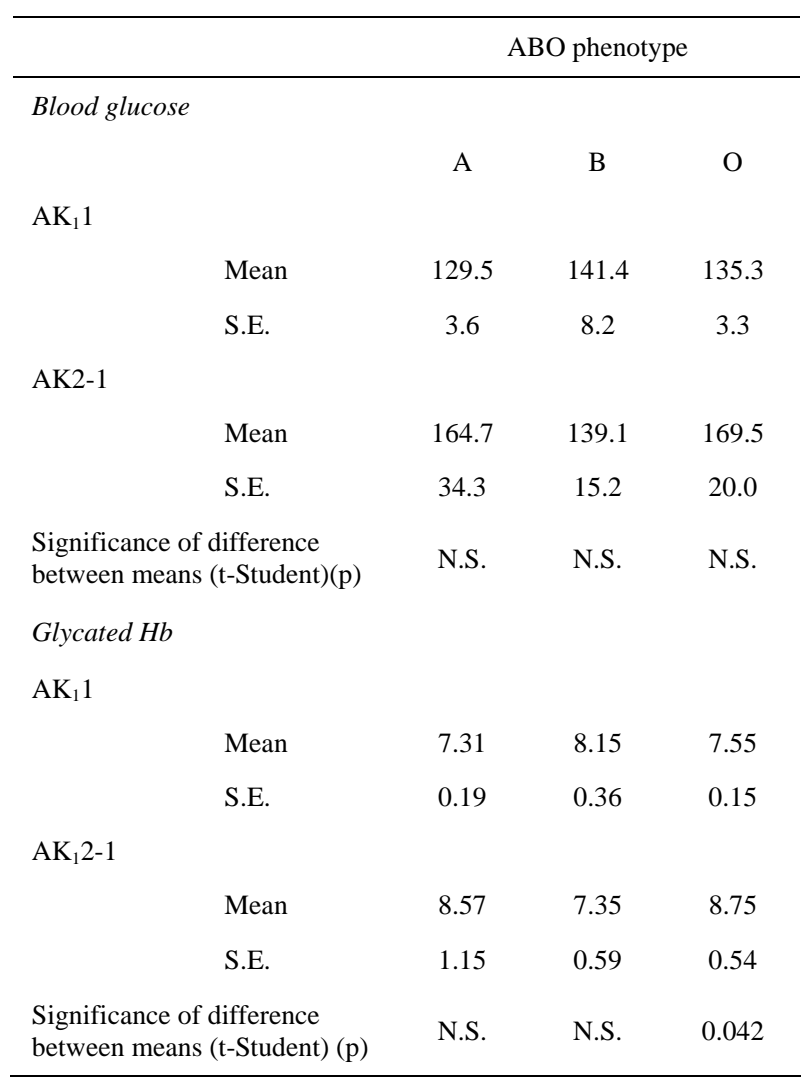

The differences in enzymatic activity between $\mathrm{AK}_{1}$ phenotypes could influence the relative concentration of ATP, ADP, AMP and adenosine influencing metabolic parameters and contributing to explain the association with clinical manifestation in T2D. Further investigation in this area could be rewarding. Our research is in line with the recent interest on genetic variants that through the regulation of insulin secretion by $\beta$-cells could be involved in the pathogenesis and clinical manifestations of type 2 diabetes. [17].

Genetic variability of $\mathrm{ABO}$ blood groups substances that are important components of cell membrane structure may influence $\mathrm{AK}_{1}$ ecto-enzyme activity thus explaining the associations reported in Tables 5 and $\mathbf{6}$.

In general high activity of $\mathrm{ACP}_{1}$ is associated with high blood glucose level. Low $\mathrm{AK}_{1}$ activity modifying the ratio among ATP, ADP and AMP may influence the effect of $\mathrm{ACP}_{1}$ activity on blood glucose resulting in lower glucose level in carriers of high $\mathrm{ACP}_{1}$ activity genotypes.

\section{CONCLUSION}

Low adenylate kinase activity associated to $\mathrm{AK}_{1} 2-1$ phenotype influencing the relative concentration of ATP, 

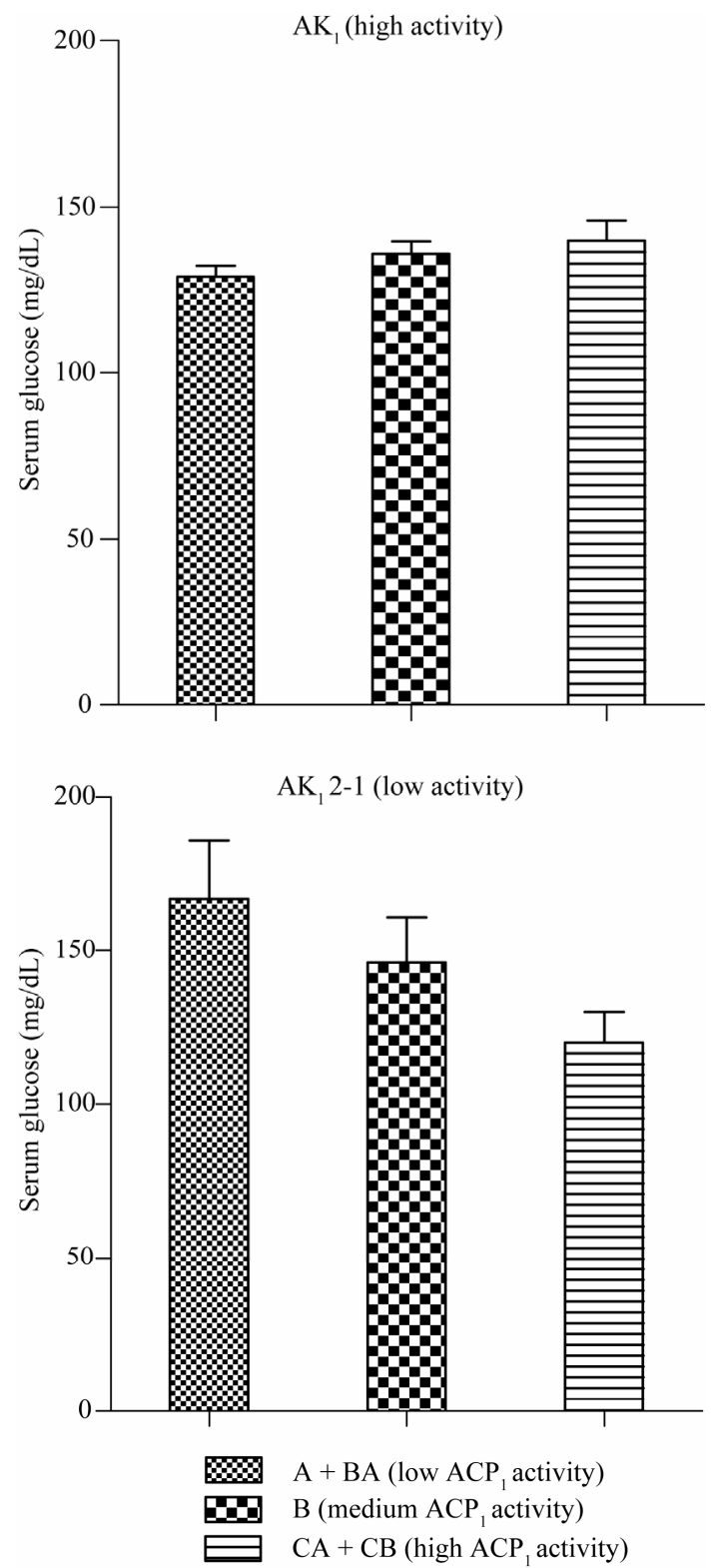

Figure 1. Blood glucose in $\mathrm{T} 2 \mathrm{D}$ patients in relation to $\mathrm{AK} 1$ and $\mathrm{ACP} 1$ phenotypes. "AK $\mathrm{ACP}_{1}$ blood glucose interaction” ACP1 three classes ((A + BA) vs B vs $(\mathrm{CA}+\mathrm{CB}))$ " $\mathrm{p}=0.079$ ACP1 two classes $((\mathrm{A}+\mathrm{BA})$ vs $(\mathrm{C}+\mathrm{CB}))$ )” $\mathrm{p}=0.030$.

ADP, AMP and adenosine could have negative effects on the clinical evolution of T2D.

\section{REFERENCES}

[1] Khakh, B.S. and Burnstock, G. (2009) The double life of ATP. Scientific American, 301, 84-90. doi:10.1038/scientificamerican1209-84

[2] Dzeja, P. and Terzic, A. (2009) Adenylate kinase and AMP signaling networks: Metabolic monitoring, signal communication and body energy sensing. International
Journal of Molecular Sciences, 10, 1729-1772. doi:10.3390/ijms10041729

[3] Matsuura, S., Igarashi, M., Tanizawa, Y., Yamada, M., Kishi, F., Kajii, T., Fujii, H., Miwa, S., Sakurai, M. and Nakazawa, A. (1989) Human adenylate kinase deficiency associated with hemolytic anemia. A single base substitution affecting solubility and catalytic activity of the cytosolic adenylate kinase. Journal of Biological Chemistry, 264, 10148-10155.

[4] Gloria-Bottini, F., Antonacci, E., Cozzoli, E., De Acetis, C. and Bottini, E. (2010) The effect of genetic variability on the correlation between blood glucose and glycated hemoglobin levels. Metabolism, 60, 250-255. doi:10.1016/j.metabol.2010.01.003

[5] Weitkamp, L.R., Sing, C.F., Shreffler, D.C. and Guttormsen, S.A. (1969) The genetic linkage relations of adenylate kinase: Further data on the ABO-AK linkage group. American Journal of Human Genetics, 21, 600- 605.

[6] Bottini, N., Gloria-Bottini, F., Borgiani, P., Antonacci, E., Lucarelli, P. and Bottini, E. (2004) Type 2 diabetes and the genetics of signal transduction: a study of interaction between adenosine deaminase and acid phosphatase locus 1 polymorphisms. Metabolism, 53, 995-1001. doi:10.1016/j.metabol.2004.03.006

[7] Fildes, R.A. and Harris, H. (1966) Genetically determined variation of adenylate kinase in man. Nature, 209, 261-263. doi:10.1038/209261a0

[8] Spencer, N., Hopkinson, D.A. and Harris, H. (1964) Quantitative differences and gene dosage in the human red cell acid phosphatase polymorphism. Nature, 201, 299300. doi:10.1038/201299a0

[9] SPSS/PC+ Version 5.0 (1992) Chicago: SPSS Inc.

[10] Sokal, R.R. and Rohlf, J.F. (1981) Biometry, WH Freeman, New York.

[11] Petit, P., Lajoix, A.D. and Gross, R. (2009) P2 purinergic signalling in the pancreatic beta-cell: Control of insulin secretion and pharmacology. European Journal of Pharmaceutical Sciences, 37, 67-75. doi:10.1016/j.ejps.2009.01.007

[12] Solini, A., Chiozzi, P., Morelli, A., Passaro, A., Fellin, R. and Di Virgilio, F. (2003) Defective P2Y purinergic receptor function: A possible novel mechanism for impaired glucose transport. Journal of Cellular Physiology, 197, 435-444. doi:10.1002/jcp.10379

[13] Misra, P. and Chakrabarti, R. (2007) The role of AMP kinase in diabetes. Indian Journal of Medical Research, 125, 389-398.

[14] Miranda, N., Tovar, A.R., Palacios, B. and Torres, N. (2007) AMPK as a cellular energy sensor and its function in the organism. Revista de Investigacion Clinica, 59, 458- 469.

[15] Remedi, M.S. and Koster, J.C. (2010) K(ATP) channelopathies in the pancreas. Pflugers Archiv, 460, 307-320.

[16] Wasada, T. (2002) Adenosine triphosphate-sensitive potassium (K(ATP)) channel activity is coupled with insulin resistance in obesity and type 2 diabetes mellitus. Internal Medicine, 41, 84-90.

[17] Chistiakov, D.A., Potapov, V.A., Khodirev, D.C., Shamkhalova, M.S., Shestakova, M.V. and Nosikov, V.V. (2009) Genetic variations in the pancreatic ATP-sensitive potassium channel, beta-cell dysfunction, and susceptibility to type 2 diabetes. Acta Diabetol, 46, 43-49. 